\title{
EL COSTUMBRISMO Y LA BOHEMIA ROMÁNTICA EN EL PERÚ: UN TRÁNSITO HACIA LA «TRADICIÓN»
}

Eva $\mathrm{M}^{\mathrm{a}}$ VALERO JUAN Universidad de Alicante

Un romanticismo sin desgarramiento no es un romanticismo. Así lo dejó escrito Luis Alberto Sánchez como idea central del capítulo que dedica al período romántico peruano en su libro Panorama de la literatura del Perú (1974), titulado significativamente «Un romanticismo frustrado». Aquí, Sánchez da algunas de las claves para entender la palidez literaria del grupo de escritores nacidos entre los años 1830 y 1835 que, hacia mediados del siglo XIX, se empeñaron en ser románticos y bohemios. Un empeño que no fue más allá de la intención, si tenemos en cuenta que la condición social de aquellos jóvenes con sueños de escritor atormentado se alejaba mucho de las desdichas y angustias de los románticos europeos; de hecho casi todos ellos gozaron de una desahogada situación en sus puestos de militares o burócratas. Las desventuras de sus modelos, Byron, Musset, Larra, Espronceda, Nerval, Shelley, sus tristezas, persecuciones y angustias no podian ser los problemas de Juan de Arona, Carlos Augusto Salaverry, Clemente Althaus, Luis Benjamín Cisneros, Arnaldo Márquez, Nicolás Corpancho o Ricardo Palma, cuya posición acomodada en la Lima de mediados del siglo XIX no casaba con tales desarreglos e infortunios:

La generación romántica -escribirá Martín Adán en su brillante ensayo De lo barroco en el Perí- hace buen papel en la historia del Perú, acaso porque no emprendió nada grande, ninguna revolución de espíritu: atenidos a todas las resultas, enviciados con su estilo y evasiva, no procuran sino estar en el Estado puesto que está el Estado. No yerran ni abusan ni propasan sino con la letra, débil e hinchada, musa de murga y estribillo (Martín Adán 1968, pág. 178). 
Dada esta íntima contradicción, los románticos peruanos tuvieron que inventar dolores y angustias que, inevitablemente, se delataban inauténticos en versos, dramas y leyendas impregnados de las lecturas de los citados europeos, a los que habría que añadir a Leopardi', Lamartine, Bécquer, Zorrilla o el Duque de Rivas. Luis Alberto Sánchez lo explica con acierto en el mentado estudio:

Un dolor así, tan discutible, impresionaba poco. La época estaba, al parecer sedienta de tristeza, más tal vez era sólo tedio lo que ahí se disfrazaba de melancolía. Y, como el romántico peruano no iba en busca de su propio ser; como era antirrousoniano, ya que no escarbaba su recuerdo ni su sensibilidad, acabó produciendo un reflejo de otros reflejos, devolviendo con ayes lecturas lacrimosas, e inventando una suerte de antología del lamento, del lamento erudito, del lamento leído, mientras en Argentina la queja viril se nutría con jugos de vida y de tragedia... (Sánchez 1974, pág. 90).

Así es, cuando en Argentina Esteban Echeverría iniciaba, tras su estancia en París, un romanticismo autóctono con su poema «La cautiva» (1837), Domingo Faustino Sarmiento escribía su Facundo (1845) para analizar la lucha gestada tras la emancipación entre civilización y barbarie, o José Mármol contextualizaba en su novela Amalia (1851) la dictadura de Rosas, en Perú -el último país emancipado de América del Sur- la literatura reflejó la tibieza con que se había acogido la independencia, más por inercia que por convicción. Recordemos que en los últimos años de la emancipación, Perú, o mejor Lima -haciendo gala de su tradicional centralismo- fue el centro de la resistencia española y por ello se convirtió en el último baluarte del rey de España, Fernando VIl. Concluida la Independencia en 1824, en la famosa batalla de Ayacucho, la perpetuación del orden colonial en un período de bonanza económica producida por el descubrimiento de los yacimientos de guano fue la señal inequívoca de que, a diferencia de otros países latinoamericanos como Argentina o México, aquí no se habían producido alteraciones substanciales, con lo que la clase criolla oligárquica y descendiente de la española siguió detentando el poder y monopolizando la cultura. El indígena, y por tanto las raíces culturales del Perú prehispánico, seguían quedando al margen, excluidos y relegados al sórdido papel que el orden colonial les había asignado. Como planteó el historiador Jorge Basadre en su ensayo «La promesa de la vida peruana» (1943) (acertada propuesta para el examen del advenimiento de la República y sus consecuencias), esa promesa de cambio con-

' Véase la influencia de Leopardi y el romanticismo italiano en Clemente Althaus, en el artículo de José Carlos Rovira titulado «Clemente Althaus y la tradición italiana» (Rovira 1995). 
substancial a la Independencia, que aguardaba ser cumplida como horizonte de expectativas, se frustró desde el comienzo².

En este contexto, la literatura que emergió tras la independencia encontró en el modelo del costumbrismo español el género más amable para la construcción literaria de la nueva Lima criolla. Ésta continuaba siendo el centro del poder en un extenso país, el Perú, en el que el secular divorcio entre la costa y la sierra -entre los criollos y los indígenas-y la consecuente problemática social, no se resolvió, como era de esperar, tras la separación de la metrópoli. El cuadro de costumbres de la clase media limeña fue el reflejo de esta realidad decimonónica en la que la Lima del presente se convirtió en protagonista indiscutible. Deliberadamente se borró el pasado de los espacios de la escritura, reservados para la representación de la actualidad en un discurso moralizante que garantizara la prosperidad del mañana, como los cuadros de Felipe Pardo y Aliaga, o a través de la punzante ironía del mejor retratista de aquella realidad, Manuel Asencio Segura. Las características del cuadro de costumbres hispánico, con Larra y Mesonero Romanos como máximos representantes, eran ideales para plasmar la nueva sociedad hispanoamericana nacida de la Independencia, de manera que el género se aclimató rápidamente a la realidad americana ${ }^{3}$.

Obviamente, las características consensuadas en la siempre polémica definición del costumbrismo se avenían con las necesidades del momento que atravesaban, en general, las naciones emancipadas: el tema del cuadro es por definición contemporáneo, está ligado a la realidad social y plantea, en la descripción de tipos y costumbres, un código que representa la tendencia aleccionadora proveniente del neoclasicismo. Esta definición contiene la problemática que ha dado

2 «No se trataba simplemente de cortar la sujeción política a España -escribe Basadre-. La Independencia fue hecha con una inmensa promesa de vida próspera, sana, fuerte y feliz» (Basadre 1992, pág. 306).

3 Raúl Porras Barrenechea destaca varios modelos hispánicos: «el costumbrismo criollo [...] provendrá en sus mejores realizaciones de Larra y de Moratín, cuando no de Bretón de los Herreros, de Mesonero Romanos, de las capilladas de fray Gerundio o de los sainetes de Ramón de la Cruz». (Porras Barrenechea 1969, pág. 43). Sobre las relaciones entre el costumbrismo peruano y el español, véase el artículo de Jorge Cornejo Polar «Costumbrismo peruano y español» (Cuadernos Hispanoamericanos, $\mathrm{n}^{\prime 2}$ 539-40, mayo-junio 1995, págs. 59-78). Para ejemplificar esta relación, Maida Isabel Watson Espener establece correspondencias entre los costumbristas más representativos de España y Perú: «El yo subjetivo de Larra encuentra su paralelo en el autor personalista y entrometido de Segura o el quejoso narrador de Pardo. El niño Goyito, personaje legendario de Pardo y Aliaga, se desarrolla a través de la caricatura, la exageración y detalles simbólicos igual que Monsieur Sans Delai, el francés de "Vuelva usted mañana» de Larra. Y, finalmente, la obsesión de Mesonero con describir en gran detalle todas las características de Madrid desembocan en los tipos limeños de Manuel Atanasio Fuentes» (Watson Espener 1980, págs. 53-54). La autora destaca además las relaciones que se establecen entre el costumbrismo peruano y el español: la ciudad como enfoque del cuadro, la representación de los estratos medios, el intento de fijar la historia de lo social, etc. 
lugar a la discusión sobre la caracterización del costumbrismo y que define el camino hacia el romanticismo: comparte con el neoclasicismo la tarea edificante a través de la corrección de costumbres, pero se asimila al romanticismo en la predilección por lo pintoresco y popular, en el intento de definir lo típicamente nacional y en su ideal de libertad formal y expresiva. Ahora bien, se aleja de él por privilegiar el presente y dar la espalda a ese pasado al que acudirán los románticos como referente principal.

Claro está, una nación, para construir los cimientos de su identidad, debe recuperar y asimilar sus raíces e integrar su historia en el presente. Obviamente, el momento de la Emancipación hubo de cancelar el pasado colonial que signifícaba la opresión y la dependencia. Pero pasados los años, hacia mediados del siglo, el proceso de recuperación histórica se hizo necesario. Y en ello la literatura iba a desarrollar un papel fundamental. El cauce fue, sin duda, la llegada del romanticismo. En el ecuador del siglo (cuando en Europa esta literatura expiraba para dejar paso a nuevas propuestas) el fervor del romanticismo invadió la antigua Ciudad de los Reyes, donde un grupo de jóvenes apasionados por las lecturas de los románticos europeos comenzó a producir una literatura centrada en la leyenda, el drama y el verso sobre temas remotos y lejanos. Sin embargo, el regreso al pasado no fue siempre a la propia historia sino también a la ajena. Esto en ocasiones produjo un desarraigo de lo nacional al confundir las lejanías de los románticos con lo exótico. La explicación de Luis Alberto Sánchez nos sigue pareciendo la más adecuada:

La característica de la «bohemia romántica» peruana, es la de cantar siempre lo remoto, dedicarse a temas lejanos, desarraigarse de lo nativo, explotar a veces lo colonial como suprema concesión a lo peruano, fomentar el teatro, insistir en el verso, favorecer la leyenda. Sus características negativas fueron: nada de novela, nada o casi nada de cuento, casi nada de drama contemporáneo en el teatro, nada de filosofía, nada biográfico, nada épico, nada tradicional auténtico (Sánchez 1974, pág. 88).

El contexto elitista de la Lima en que estos escritores nacieron no les dejaba atisbar lo que ocurría tras las cumbres de los Andes. Y la lejanía temporal que asumieron, cuando volvían al pasado propio, no traspasó los límites del período colonial, especialmente desde el siglo XVIII en adelante. Seguramente ese es el motivo central que explica lo postizo de una literatura que, por romántica, debería haber sido el cauce para penetrar en las raíces ancestrales de la neonata república, o para recuperar de manera más consistente el período colonial. A ello hay que añadir la palpable imitación de los modelos a la que nos hemos referido con Luis Alberto Sánchez, sobradamente analizada con anterioridad por otros críticos, escritores e historiadores de la literatura desde comienzos del siglo XX. Así por ejemplo, José de la Riva Agüero, en su Carácter de la literatura del Perú inde- 
pendiente (1905), y con su habitual actitud hispanizante, explica que los modelos románticos asumidos fueron, fundamentalmente, los españoles:

$Y$ nuestro grupo de románticos aunque leyera y estudiara asiduamente a Lamartine y Hugo, se inspiraba de preferencia en el romanticismo español. Del inglés, del alemán y del italiano, sería difícil encontrar en ellos influencias inmediatas y persistentes. Se aflojaron algo, pero estuvieron muy lejos de romperse, los lazos de subordinación que unían nuestras letras a las de la madre patria (Riva Agüero 1962, pág. 136).

Esta valoración es sin duda muy generalizadora si recordamos, por ejemplo, el impacto de la literatura italiana (la renacentista y la contemporánea romántica) en uno de los principales románticos peruanos, Clemente Althaus. Este impacto ha sido analizado por José Carlos Rovira en su estudio «Clemente Althaus y la tradición italiana», donde plantea la reinterpretación romántica realizada por Althaus en sus traducciones de Petrarca, Dante, Ariosto, Pietro Bembo, entre otros (aparecidas en el diario El Comercio de Lima en 1873 y 1874 y publicadas por Estuardo Núñez en la edición de Sonetos italianos, 1957):

La selccción de poemas -escribe Rovira- y la determinación de las imágenes de ellos por los títulos leídos nos plantea inmediatamente una perspectiva romántica: la mujer, Laura, como mecanismo de evocación cordial sobre todo in morte; la noche, o retazos de una naturaleza emocional, son, desde la forma de nombrar a los poemas, una manera de introducirlos en un panorama frecuente en el paradigma romántico. [...] encontraremos además el amplio tono de intervención emocional que Althaus pone en sus traducciones petrarquescas, y la presencia de determinadas secuencias que son reelaboraciones, dentro de su paradigma temporal, de la poesía de Petrarca (Rovira 1995, págs. 70-71).

En este trabajo, además, José Carlos Rovira reinterpreta la presencia de Leopardi en Althaus para proponer una perspectiva distinta a la realizada por Menéndez Pelayo en su Historia de la poesía hispanoamericana sobre el poema el «Último canto de Safo», donde el polígrafo español consideró que Althaus realizó una mala imitación que «aspiró a la pureza clásica sin conseguirla más que de lejos» (Menéndez Pelayo 1948, págs. 186-187). Para José Carlos Rovira, sin embargo, «lo que parece indudable es, más que la imitación leopardiana, el impacto de una globalidad cultural que el romanticismo italiano ha restituido» (Rovira 1995, pág. 79). El caso de Althaus es, en definitiva, un ejemplo muy claro de la simplificación en la valoración de Riva Agüero sobre la hegemonía del modelo español para los románticos peruanos.

En este mismo sentido, hay que recordar también la opinión de Ventura García Calderón, quien sitúa el paradigma de imitación del romanticismo peruano 
en el francés y el español ${ }^{4}$. Pero al margen del modelo específico europeo asumido por los románticos peruanos (que requeriría de análisis individualizados como el propuesto por José Carlos Rovira para el caso de Althaus) todos los críticos coinciden en subrayar la extrañeza y superficialidad de un romanticismo que no se aclimató en suelo peruano. García Calderón, en una de las obras principales de análisis del momento romántico, Del romanticismo al modernismo: prosistas $y$ poetas peruanos, califica al romanticismo peruano de «brusca epidemia», para continuar desarrollando la misma idea:

¿Quién podrá resolver el enigma? La más inteligente sutileza no encontraría razones plausibles a la inesperada locura. Porque, en realidad, ningún otro pueblo menos romántico que el peruano. [...] Se lloró porque Lamartine había llorado. Se embocó la trompeta heroica porque Víctor Hugo había cantado la leyenda de Napoleón [...] Al mismo tiempo, los jóvenes poetas sabían de memoria los cantos de Zorrilla, de Espronceda y de Bécquer. [...] Cuando los leo no puedo menos que sonreír. Pienso en la escasa sinceridad de esta poesía. No era un estado del alma, sino un pasatiempo literario (García Calderón 1910, pág. VII).

Pero ni siquiera sería necesario acudir a los críticos e historiadores para entender la falla del movimiento romántico en Perú. Basta con acudir al documento esencial sobre este momento literario, producido por uno de los integrantes del grupo. Me refiero a Ricardo Palma, quien, en el texto titulado La bohemia de mi tiempo, de 1896, nos ofrece un divertido cuadro, en forma de confidencia, sobre los primeros años de su propia «existencia literaria»; años en los que, nos dice, fue «un bohemio matriculado». Con este texto Palma etiquetó a su grupo de juventud con la dénominación de «bohemia», y en él periodiza el desarrollo del romanticismo -o, como él lo califica, la etapa de «la filoxera literaria»- entre 1848 y 1860 . Siempre fiel a su particular tono irónico, recuerda en este texto el encendido entusiasmo con que aquellos jóvenes peruanos recibieron la oleada romántica proveniente de Europa:

Nosotros, los de la nueva generación, arrastrados por lo novedoso del libérrimo romanticismo, en boga a la sazón, desdeñábamos todo lo que a clasicismo tiránico apestara, y nos dábamos un hartazgo de Hugo y Byron, Espronceda, García Tassara y Enrique Gil. Márquez se sabía de coro a Lamartine; Corpancho no equivocaba letra de Zorrilla; para Adolfo García, más allá de Arolas no había poeta; Llona se entusiasmaba con Leopardi; Fernández, hasta en sueños recitaba las Doloras de Campoamor; y así cada cual tenía su vate

${ }^{4}$ «Influyen, sin duda, en los poetas, Bécquer, Espronceda, Meléndez Valdés, pero sobre todo Víctor Hugo, Lamartine y Musset. Como Palma, Salaverry y Cisneros, algunos de nuestros románticos vivieron años de juventud en París; todos conocen el francés» (García Calderón 1914, pág. 60). 
predilecto entre los de la pléyade de revolucionarios del mundo viejo. De mi recuerdo que hablarme del Macias de Larra, o de las Capilladas, de Fray Gerundio, era darme por la vena del gusto (Palma 1964, pág. 1294).

Fruto de esta «filoxera» -de esta plaga literaria- son obras como: Albores $y$ destellos (1871) de Carlos Augusto Salaverry; Notas perdidas (1862) de José Arnaldo Márquez; Cuadros y episodios peruanos (1872) de Pedro Paz Soldán y Unanue (Juan de Arona); los Ensayos poéticos (París, 1854) y los dramas El poeta cruzado (1848) y El Templario (1855), de Manuel Nicolás Corpancho; poemas de Althaus como El último canto a Safo, El desahuciado, A orillas del mar, A mi patria... o los fragmentos de su Diario de un viajero americano; la novela titulada Julia (1860) de Luis Benjamín Cisneros, etc. De este último se pueden recordar también El pabellón peruano y Alfredo el sevillano como ejemplos de aquellos fallidos dramas históricos que, a imitación de Hugo, Dumas o García Gutiérrez masificó la desatada bohemia en un corto espacio de tiempo.

Sin embargo, al margen de lo hasta aquí planteado, y a pesar de esa palmaria imitación de los modelos europeos, el romanticismo fue esencial en la evolución de la literatura peruana para la gestación de un género propio y genuino que sí se aclimató para siempre en el imaginario popular de los peruanos: la «tradición» creada por Ricardo Palma.

Hasta la fatídica fecha de 1879, cuando la vecina Chile invadió el Perú dando lugar a la cruenta Guerra del Pacífico, Lima fue, de algún modo, una ciudad en tránsito que, tras la Independencia, parecía adormecida en la sensualidad y la frivolidad de la vida criolla, tan sólo levemente alterada por motines sin demasiada relevancia. Del mismo modo, la literatura que allí se produjo hasta la citada fecha pareció ser también un tránsito fundamental para la evolución hacia la expresión genuina en un género de cuño propio, la «tradición». Porque si tras la Independencia el cuadro de costumbres impuso el retrato de la cotidianidad del presente, anulando el pasado colonial como necesidad patriótica de la nueva república, el romanticismo tuvo la importancia de suscitar el regreso al pasado a través del drama histórico y de la leyenda. Cuando no se perdieron en exóticas lejanías, extrañas a lo peruano, los románticos exploraron la historia que la generación anterior había desestimado para llevar a cabo la operación inversa: escribir sobre el pasado colonial y eludir la realidad contemporánea ${ }^{5}$. Y al igual que en el momento de la emancipación los escritores pudieron traducir el espíritu contemporáneo de la independencia en el cuadro de costumbres, como género que posi-

${ }^{5}$ Como ha visto Pedro Henríquez Ureña, este proceso literario afecta a todo el ámbito de América Latina: «Los tres siglos de la Colonia, que habíamos empezado a imaginar como nuestra edad de las tinieblas, aparecen también en nuestro teatro y en nuestra literatura de imaginación» (Henriquez Ureña 1994, pág. 134). 
bilita el retrato del presente, los «bohemios» encontraron en la predilección por el pasado el ámbito literario ideal para la que iba a ser una necesaria recuperación de la conciencia histórica tras el caos de la República.

Así, lo que fuera la leyenda romántica, y sus fantásticas evocaciones, se metamorfoseó con la asimilación de nuevos ingredientes dando lugar a la «tradición». El romanticismo de aquellos bohemios que se quisieron desventurados, fue, en definitiva, un tránsito de obligado recorrido para la gestación y el nacimiento de la «tradición»; un género nuevo que arraigó profundamente en el imaginario colectivo de Lima, fijando en la memoria de los limeños un pasado que, por imaginario, fue asumido como historia legendaria de la ciudad. La conciencia histórica había renacido por tanto en esta generación que se sumerge en la memoria de la colonia, de forma que los románticos abrieron un nuevo camino de penetración en la historia y en su literatura. $Y$ aunque algunos no hallaron la fórmula idónea para adentrarse en ese camino, sí que crearon el clima adecuado para que de entre ellos surgiera la figura de Ricardo Palma, que será central para la asimilación del universo colonial. El polígrafo que demostró su pasión por el mundo de las letras en una densa trayectoria vital que le permitió ser escritor, Miembro Correspondiente de la Real Academia Española, Director de la Academia Peruana de la Lengua, lexicógrafo, editor, Director de la Biblioteca Nacional de Perú, etc., promovió, y realizó en sus Tradiciones peruanas, no sólo una ingente tarea de recuperación histórica, sino también una labor de rescate de la literatura, preferentemente hispánica, de los siglos anteriores. Con ello consiguió revivir y preservar, además, un espacio de poesía popular. Sobre todo a través de la creación de una intertextualidad a través de la cual pudo entablar un riquisimo diálogo con sus antepasados literarios, produciendo así una nacionalización de la tradición literaria colonial (Vid. Cornejo Polar 1989, págs. 43-57).

Pero para entender los motivos del arraigo del nuevo género, es preciso desentrañar la nueva receta literaria ensayada por Palma, cuyos ingredientes revelan la importancia del costumbrismo y el romanticismo en esta evolución esencial de la literatura del Perú.

Para acercarnos a la definición de la «tradición», es imprescindible recordar aquella máxima en la que Palma dejó claro el límite entre el género que estaba creando y la historia propiamente dicha: «El tradicionista -escribe- tiene que ser poeta y soñador; el historiador es el hombre del raciocinio y de las prosaicas realidades»r. El sueño de Palma, precisamente, fue el de la historia, por lo que el ingrediente privilegiado por los románticos -entre los que se había contado-, es decir, el viaje literario hacia un tiempo remoto, animó, desde la publicación de la primera serie de las Tradiciones peruanas en 1872, toda su producción literaria posterior. Exceptuando este factor fundamental, desde el momento en que el poeta se convirtió en tradicionista el ideario romántico quedó en los anaqueles de su 
memoria. El nuevo escritor se desprendió definitivamente del juvenil arranque imitativo para lanzarse a una aventura en solitario: el ensayo de una creación novedosa y original. José Miguel Oviedo, en su libro titulado Ricardo Palma, explica este tránsito o evolución experimentada por el escritor:

Al consagrarse al «culto del pasado» y reinventar, sobre el cañamazo de nuestra Colonia y República, los pequeños mitos de la historia peruana, Palma ha iniciado un camino divergente al de la «bohemia» nacional. Ese proceso de alejamiento se extiende, más o menos, entre el 60 , fecha límite de su participación activa en el grupo (es el año de su exilio en Chile), y el 72, en que Palma parece tener una plena conciencia de que el pasado histórico en que él decide vivir no es el pasado ideal de los románticos. El ideario del romanticismo ya no le sirve al escritor de tradiciones, que busca la poesía en archivos e infolios, no en meras fugas idílicas al mundo de ayer ni en medievalismos de cartón. Su convición de estar iniciando "algo muevo» en la literatura peruana lo lleva a autotitularse iniciador de la tradición en América [La cursiva es mía]. (Oviedo 1968, pág. 25).

Palma creó por tanto el viaje irrepetible hacia el pasado a través de una inédita conjunción que nadie antes había cultivado: la fundación literaria de la historia -preferentemente colonial, pero también, aunque en menor medida, incaica y republicana- y, como fiel discípulo del costumbrista Segura, la visión criollista, popular y chispeante de la literatura costeña. A esta última la enriqueció con la marca inconfundible de un estilo, al que la oralidad, unida al recuerdo, imprime su peculiaridad formal. Pero la plasmación del habla popular dista mucho de generar un estilo descuidado en su escritura. Para Palma, la esencia de la «tradición» estaba en la forma y no tanto en el fondo de lo narrado, pues en ella se revela el pretendido espíritu popular de esta literatura: «A mis ojos la tradición no es un trabajo que se hace a la ligera: es una obra de arte. Tengo una paciencia de benedictino para limar y pulir mi frase. Es la forma más que el fondo lo que las hace populares» (carta a Vicente Barrantes) (en Cornejo Polar 1998, pág. 147). El fruto de esta hibridez entre el criollismo popular y la predilección por el pasado, que combinaba y reformulaba las características inherentes a las corrientes costumbrista y romántica, fue este género fundacional por la novedad que introdujo en el panorama de la literatura peruana del momento.

En este amago de definición se encuentra la «tradición», considerada la primera creación original que recibe influencias obvias de ambas corrientes literarias, pero que se configura como una literatura diferente. Ventura García Calderón incide en ese carácter fundacional de las «tradiciones» de Palma como propuesta literaria genuina del Perú cuando, comparándolas con la literatura inmediatamente anterior (la costumbrista y romántica), escribe: 
El individualismo exasperado de los románticos, característico de la escuela violenta, debía de parecer una exageración inmotivada a este pueblo tranquilo, donde el robusto personalismo de los primeros conquistadores se transformaba en pereza; [...] todos estos sentimientos frenéticos eran extranjeros a una raza apacible, realista, superficial en religión, profundamente sociable. [...] mientras los unos proferían lamentos, los otros simplemente reían. [...] Como no existen, en el pequeño medio, crisis violentas, vida intensa, en vez de escribir vastas novelas se trazan en miniatura artículos de costumbres. [...] Pero lo más nacional, lo más original también de esta vena criolla, es la «tradición» de Ricardo Palma (García Calderón 1910, págs. XIV y XV).

Algunas de las definiciones más esclarecedoras de este género las encontramos en textos de historiadores principales. Conviene recordar aquí algunas de ellas para comprender la trayectoria literaria que estamos trazando, por ejemplo la de José Miguel Oviedo, para quien la «tradición» es

un género híbrido, pues, una mixtión o precipitado de los más dispares ingredientes [...] Es un cruce de raro equilibrio, el fruto de un mestizaje literario que funde alegremente lo vernáculo y lo clásico, lo limeño y lo hispánico, la historia y el cuento (Oviedo 1968, pág. 32).

En esta hibridez literaria incide también la definición de Porras Barrenechea:

[Es un] producto genuino limeño y criollo. No es historia, novela, ni cuento, ni leyenda romántica. De la historia recoge sus argumentos y el ambiente, pero le falta la exactitud y el cuidado documental. Palma no concibe la historia sin un algo de poesía y de ficción...

La «tradición» es, pues, un pequeño relato que recoge un episodio histórico significativo, anécdota jovial, lance de amor o de honra, conflicto amoroso o político en que se vislumbra repentinamente el alma o las preocupaciones de una época o se recoge intuitivamente, por el arte sintético del narrador, una imborrable impresión histórica. [...] Es la gran historia realizada con la técnica fragmentaria y liviana del pintor de azulejos. [...] Es la historia popular contada, según lo dijo él mismo, como la cuentan las viejas y el vulgo... (Porras Barrenechea 1969, págs. 57-59).

Sin duda el acierto de Palma consistió en conseguir transformar el costumbrismo, tomando de él su carácter satírico y pintoresco y dotando al cuadro de una irrefrenable riqueza imaginativa. La ironía asimilada en escritores españoles como Bretón de los Herreros, Estébanez Calderón o Larra, unida a la sonrisa mordaz de su maestro Segura, y de otros maestros anteriores de la sátira peruana como Caviedes o Esteban de Terralla y Landa, se perpetuaba en las Tradiciones, comenzando a consolidarse así como rasgo propio de una tradición literaria costeña fundamental en la historia de la literatura del Perú. 
El resultado de la amalgama entre la sátira, la historia y la inventiva del escritor, son varias colecciones de lo que ya podemos denominar relatos, en los que Palma, sobre el substrato de la historiografía peruana, encuentra el anecdotario para la creación de sus «tradiciones». El carácter fundacional de esta literatura puede situarse por tanto en tres niveles: por evolución de la escritura costeña (de Caviedes a Segura), fundación del criollismo como un proyecto literario propio; nacimiento del cuento como género de honda raigambre nacional, en el que por primera vez -anticipándose a la novela-, se mitifica la historia peruana (véase Enrique Pupo Walker 1995, pág. 51); y, por último, la primera fundación literaria de Lima en un corpus literario prolífico y consistente.

La creación del espacio imaginario de Lima se desarrolló así en una escritura y un género propiamente peruano que se deshacía de entumecidas imitaciones $y$, paliando la inanidad de la historia literaria de la Lima colonial, aportaba un amplísimo corpus textual a la construcción poética de la ciudad. Como vio Jorge Cornejo Polar, en el afán declarado por Palma de marcar un límite claro entre América y la vieja metrópoli,

la forma literaria «tradición palmiana» venía a ser, luego del «yaraví melgariano») (aunque se trata evidentemente de modos creativos diferentes), la segunda especie literaria auténticamente originaria del Perú mestizo, una suerte de espontánea superación de la consabida dependencia cultural en relación con Europa y una significativa afirmación de identidad peruana [La cursiva es mía]. (Cornejo Polar 1998, pág. 149).

Pero, además de lo dicho hasta aquí, ¿dónde se encuentra la explicación principal de esta originalidad? Sin duda la clave para la invención del mito urbano en este género primerizo por lo original de sus formas y contenidos, se encontraba precisamente en el límite marcado con la historia, es decir, en el proceso de creación imaginaria de esa historia. El poeta Martín Adán, en su ensayo De lo barroco en el Perú, aboca su genio creativo en el comentario sobre la construcción de la Lima imaginaria lograda por Palma en las Tradiciones:

Palma hace de la imprecisión su mejor instrumento, su prodigioso tirafondo: con una fecha, un refrán, una sonrisa y un nombre hace un párrafo henchido de verdad transparente. Detrás de Palma, no está sino la sombra de la Lima que inventa. La Lima sustancial e indispensable del limeño está entre éste y Palma, la deseamos, la reparamos y la ganamos. [...] Muchísimo más ha dicho de verdadero la mentira cordial, la euforia cabal, que la probidad narrativa o descriptiva (Martín Adán 1968, págs. 17-18).

Así es. La imprecisión de lo narrado, uno de los rasgos característicos de la memoria oral, está en la base de la invención del mito urbano, y de ella surge esa Lima inventada en las Tradiciones peruanas, tan debatida con posterioridad en la 
polémica suscitada sobre la versión del pasado que de ellas se desprende y sobre el valor histórico -juzgando la obra en términos de veracidad o falsedad histórica- de ese pasado. Desde mi punto de vista, cualquier esfuerzo en este ámbito crítico parece inútil, porque Palma, a pesar de conferir veracidad a los hechos que narra, no pretendió en ningún momento hacer historia, tal y como explicita en determinados fragmentos de algunas de sus «tradiciones»:

[...] aquí pongo punto: primero, porque, como ya to he dicho, no me propongo historiar; y segundo, porque lo que pudiera escribir no tendría la menor concomitancia con la Conga [La cursiva es mia]. (Palma 1894, tomo IV, págs. 315 y 318$)$.

La ciudad de las relajadas costumbres y de los lances románticos, como el protagonizado por el famoso Virrey Amat con la comedianta que él moteó con el nombre de Perricholi, llenan las páginas de las Tradiciones peruanas. En ellas emerge aquella «Ciudad de la gracia» que vio Rubén Darío cuando exaltó la capital peruana y enalteció a sus míticos escritores y fundadores, entre ellos, Ricardo Palma, de quien dijo: «Es el primer limeño de Lima» (Cit. en Luis Alberto Sánchez 1927, pág. 27). Así, desde fines de siglo a Palma le fue otorgado el título de fundador literario de la capital, o de cronista clásico de la Lima del pasado. A través de la fusión de los rasgos que hasta aquí hemos intentado definir como consubstanciales a la «tradición», Palma creó la Lima del imaginario popular, se negó a ser el «hombre del raciocinio y las prosaicas realidades», infundió aliento a la historia que le servía para precisar el marco o contexto en el que actuaban sus personajes-, y recorrió en su imaginación «la ciudad silenciosa de la conquista» (Ihid., pág. 54), monótona, apacible y pueblerina, y la ciudad en que vivió, entristecida y pobre tras el embrollado proceso republicano; aldea silenciosa como en la colonia, pero ahora con tonalidades y matices decadentes. En suma, construyó una Lima mítica y poética a través de la anécdota colorista, tan distante de la precisión del historiador, y, como hemos comprobado en los fragmentos citados, sustituyó la provecta veracidad histórica por el pintoresquismo de la leyenda popular, que le permitió dotar a la ciudad del embrujo de su alma graciosa y singular.

Luis Alberto Sánchez, en el libro que dedica a la ciudad creada por Palma, acierta en utilizar en el último capítulo el «Símbolo de Gulliver» para el análisis de esa Lima imaginaria pintada con sonrisas y excesos: «para la pequeñez del asunto, sus ojos tuvieron exageraciones macroscópicas. [...] trató de revivir la época, valiéndose de anécdotas y leves aventuras, agigantadas por su imaginación» (Ibid., pág. 111). Nos mostró, en suma, una Lima encantadora y poética, que ocultaba esa otra cara de la ciudad cochambrosa por la que paseaban no sólo los refinados limeños del siglo XVIII sino también los típicos gallinazos para escarbar desperdicios por las calles polvorientas, llenas de suciedad e inmundicia. En este sentido, Sánchez ratifica que lo disímil entre la Lima de Palma y la ciudad 
real del pasado «muestra que hay derecho a suponer que en la sonrisa de Don Ricardo está la clave de su obra» (Ibid., pág. 127).

En definitiva, la «tradición» logró una singularidad producto de esa receta que combina la historia, la leyenda y la literatura; fusión de la que surgen estos peculiares relatos en los que la ciudad virreinal revive sus fastos. En las Tradiciones, los limeños de la urbe republicana, saturados de historia entre real e inventada, podían adivinar en cada calle de su ciudad una anécdota del tradicionista, de forma que el hortus clausum virreinal (aquel «huerto cerrado» por las murallas construidas en 1685 que simbolizaron la cerrazón elitista de la Lima colonial) se impregna de historia y de leyenda y se integra decididamente en la conciencia republicana de mediados de siglo. De ahí su especial relevancia en el devenir de las letras del Perú. Porque, como plantea Luis Fernando Vidal, «Palma integra los tiempos y los sucesos de nuestra historia en el universo cerrado de la ciudad antigua, generando la idea de continuidad» (Vidal 1986, pág. 16). De esa integración surge una revalorización de lo genuinamente limeño, que se encuentra adherido en su más auténtica expresión a las clases medias de la sociedad virreinal. Y Palma, divertido y socarrón, se entusiasma con estos agudos personajes que hacen alarde de ingenio y donosura, empecinándose en el realce de lo propio y autóctono, llevado a la exageración y a la caricatura. Tanto es así, que Porras Barrenechea le denominó «el más grande forjador de peruanidad» (1954, pág. $20)$.

Un buen ejemplo entre tantos otros podría ser «La tradición de la saya y el mantoy, narración más cercana en este caso a la crónica de costumbres que al relato. Aquí, Palma pretende hacer memoria de esta moda femenina remontándose al año 1560 hasta llegar al siglo XIX, para darnos el testimonio directo de su desaparición. Pero lo más interesante es la manera en que el escritor describe dicha moda como una de las características principales y exclusivas que identifican, diferencian y confieren personalidad propia a la Lima de la Colonia:

Tratándose de la saya y el manto, no figuró jamás en la indumentaria de provincia alguna de España ni en ninguno de los reinos europeos. Brotó en Lima tan espontáneamente como los hongos en un jardín.

[...] Nadie disputa a Lima la primacía, o mejor dicho la exclusiva, en moda que no cundió en el resto de América... (Palma 1994, págs. 625-626).

En este ejemplo comprobamos el afán de Palma por la captación de lo autóctono limeño, así como la cerrazón de una Lima exclusiva cuya costumbre en la vestimenta femenina «nunca salió del radio de la ciudad». El anhelo de distinción es equiparable a la esencia de la «tradición», que se instaura como género propio; al igual que la saya y el manto, la «tradición» «nunca figuró en provincia alguna de España ni en ninguno de los reinos europeos». En suma, la «tradición» 
venía a culminar un proceso: la independencia de las letras desde la fecha en que se logró cortar el cordón umbilical con la metrópoli, que atenazaba a los países hispanoamericanos, con especial incidencia en la que fuera la mejor colonia de España, el Virreinato del Perú. La emancipación literaria, tras las quejas y los ayes inventados por aquellos románticos que soñaron una imposible bohemia, llegaba con estos relatos que, por no ser tales (es decir, por la pecualiaridad analizada en estas páginas) significaron el nacimiento en el Perú de una literatura nacional. 


\section{BIBLIOGRAFÍA CITADA}

BASADRE, Jorge, 1992. La promesa de la vida peruana, en Perú: problema y posibilidad y otros ensayos, Caracas, Ayacucho.

CORNEJO POLAR, Jorge, 1995. «Costumbrismo peruano y español», Cuadernos Hispanoamericanos, 539-40 (mayo-junio), págs. 59-78.

- 1998. «Palma, entre el costumbrismo y la novela», en Estudios de Literatura Peruana, Lima, Universidad de Lima y Banco Central de Reserva, págs. 141-153

- 1998b. «Costumbrismo y periodismo en el Perú del siglo XIX», en Estudios de Literatura Peruana, Lima, Universidad de Lima y Banco Central de Reserva, págs. 75-105.

CORNEJO POLAR, Antonio, 1989. "Capítulo II: La nacionalización de la herencia colonial»; en La formación de la tradición literaria en el Perú, Lima, Centro de Estudios y Publicaciones, págs. 43-57.

GARCía CALDERón, Ventura, 1910. Del romanticismo al modernismo: prosistas y poetas peruanos, París, Sociedad de ediciones literarias y artísticas.

-1914. La literatura peruana (1535-1914), en la Revue Hispanique, tomo XXXI, New York, París.

Henríquez Ureña, Pedro, 1994. Las corrientes literarias en la América Hispánica, México, Fondo de Cultura Económica.

MARTín AdÁn (Rafael de la Fuente Benavides), 1968. De lo barroco en el Perú, Lima, Universidad Nacional Mayor de San Marcos.

MEnÉndez Pelayo, Marcelino, 1948. Historia de la poesia hispanoamericana, Madrid, CSIC.

Oviedo, José Miguel, 1968. Ricardo Palma, Buenos Aires, Centro Editor de América Latina.

PALMA, Ricardo, 1894. Tradiciones peruanas, Barcelona, Montaner y Simón.

- 1964. La bohemia de mi tiempo; en Tradiciones Peruanas Completas, Madrid, Aguilar, $5^{\text {a }}$ ed.

- 1994. Tradiciones peruanas (selección), Madrid, Cátedra.

PORRAS BARRENECHEA, Raúl, 1969. El sentido tradicional de la literatura peruana, Lima, Instituto Raúl Porras Barrenechea.

- 1954. Tres ensayos sobre Ricardo Palma, Lima, Juan Mejía Baca. Los tres ensayos son: «Palma satírico», «Palma romántico» y «Palma y Gonzalves Días».

PUPo WALKer, Enrique, 1995. «Prólogo»a El cuento hispanoamericano, Madrid, Castalia.

SÁNCHEZ, Luis Alberto, 1974. «Un romanticismo frustrado»; en Panorama de la literatura del Perí, (desde los origenes hasta nuestros dias), Lima, Milla Batres, págs. 79-100. 
- 1927. Don Ricardo Palma y Lima, Lima, Imprenta Torres Aguirre.

RovirA, José Carlos, 1995. «Clemente Althaus y la tradición italiana»; en Entre dos culturas. Voces de identidad hispanoamericana, Alicante, Universidad de Alicante, págs. 63-80.

VIDAL, Luis Fernando, 1986. «La ciudad en la narrativa peruana», en VVAA, Presencia de Lima en la literatura, Lima, Centro de Estudios y Promoción del Desarrollo.

VILlAnes CAiro, Carlos, 1994. «Prólogo» a su edición de Ricardo Palma, Tradiciones peruanas, Madrid, Cátedra.

WATSON ESPENER, Maida Isabel, 1980. El cuadro de costumbres en el Perí decimonónico, Lima, Pontificia Universidad Católica del Perú. 